\title{
Erratum zu: \\ Die menschengerechte Gestaltung der Arbeitswelt - gesunde Organisationsentwicklung
}

Ralf Neuner und Susanne Delfs

\section{Erratum zu:}

Kapitel 4 in: R. Neuner, Psychische Gesundheit bei der Arbeit, https://doi.org/10.1007/978-3-658-34974-5_4

Das vierte Kapitel wurde versehentlich mit einem Fehler veröffentlicht. In Abbildung 4.5 wurde das Wort „Copyright“ gelöscht. Das Kapitel wurde mit den Änderungen aktualisiert.

\section{Abb. 4.5}

Eisenhower-Matrix. Quelle:

https://erfolgreich-projekte-leiten.de/eisenhow

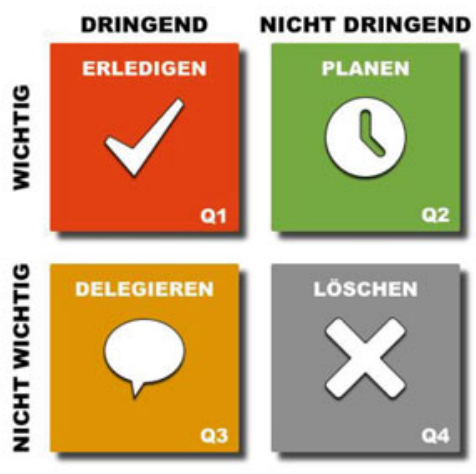

Die aktualisierte Version des Kapitels finden Sie unter

https://doi.org/10.1007/978-3-658-34974-5_4

(C) Springer Fachmedien Wiesbaden GmbH, ein Teil von Springer Nature 2021 